\title{
LA ORDENACIÓN DE UN FONDO DE CARTOGRAFÍA INÉDITO DE LA REAL SOCIEDAD COSMOLÓGICA DE SANTA CRUZ DE LA PALMA*
}

\author{
Manuel Álvarez Fernández** \\ Universidad de La Laguna
}

\section{RESUMEN}

Con este trabajo se pretende dar a conocer la existencia de un fondo de cartografía inédito perteneciente a la Real Sociedad Cosmológica de Santa Cruz de La Palma, así como las labores de limpieza, análisis y ordenación llevadas a cabo para su presentación. Aborda, además, la importancia que reviste para las bibliotecas y archivos la necesidad de la correcta conservación y tratamiento de los fondos documentales, ya que constituyen el patrimonio, la memoria y la identidad de un territorio, al servicio siempre de la cultura y de sus ciudadanos. PALABRAS Clave: cartografía, fondo, conservación, biblioteca, archivo.

\section{THE ORDINATION OF AN UNFINALED CARTOGRAPHY \\ FUND OF THE ROYAL COSMOLOGICAL SOCIETY \\ OF SANTA CRUZ DE LA PALMA}

\section{Abstract}

This work aims to introduce the existence of an unpublished cartography fund belonging to the Royal Cosmological Society of Santa Cruz de La Palma, as well as the cleaning, analysis and ordering work carried out for its presentation. In addition, it aproaches the importance for libraries and archives of the need for the correct conservation and treatment of documentary collections, since they constitute the patrimony memory and identity of a territory, always at the service of culture and its citizends.

KEYwORDs: cartography, fund, conservation, library, archive.

DOI: https://doi.org/10.25145/j.histcan.2019.201.01

Revista de Historia Canaria, 201; mayo 2019, pp. 11-40; ISSN: e-2530-8270 


\section{INTRODUCCIÓN}

"Los mapas son los ojos de la historia», afirmaba Gerardus Mercator, uno de los cartógrafos más recordados y el hombre que cambió nuestra visión del mundo.

Representar y medir el mundo que nos rodea ha sido siempre una tarea estrechamente ligada a la evolución del hombre, sobre todo, en su afán de entender el espacio en que habita, su entorno y los lugares más alejados.

Mucho antes de la invención de la escritura, la humanidad se ha comunicado o ha dejado constancia de sus ideas por medio de signos o ideogramas. En este caso los mapas van a constituir una de estas representaciones, cuyo objeto, independientemente del tipo de cultura, será representar diversos puntos y accidentes de la tierra y la relación que entre ellos va a establecer el hombre. Por lo que, desde épocas muy antiguas, comienzan a confeccionarse con una finalidad de carácter instrumental para la determinación de distancias, establecer rutas y recorridos o identificar localizaciones que facilitaran el desplazamiento.

El mapa, si es visto a partir de su evolución a lo largo de la historia, refleja el pensamiento cambiante de la especie humana, y pocas de sus obras constituyen un indicador tan excelente de cultura y civilización ${ }^{1}$.

Es habitual que al hablar de fuentes históricas se olvide el papel que pueden desempeñar los mapas, ya no solo como complemento de análisis y conocimiento de los procesos históricos, sino como una fuente en sí mismos.

Las fuentes históricas constituyen la materia prima de la historia, es decir, comprenden todos los documentos, testimonio u objetos que nos transmiten una información significativa para la reconstrucción, el análisis y la interpretación de los acontecimientos históricos. Según su origen, las fuentes pueden ser primarias -proceden de la época que se está investigando, testimonios de primera mano, contemporáneas a los hechos-o secundarias - elaboradas con posterioridad al período que se está estudiando-. También pueden ser clasificadas según su soporte: escritas o textuales, gráficas o estadísticas, iconográficas, cartográficas, materiales, orales, etc.

El mapa -un modelo universal de expresión y concepción de una triple realidad: ideológica, gráfica y geográfica- va a constituir un tipo de documento o fuente que, por su propia naturaleza, es susceptible de transformarse en un elemento esencial para la exposición de hechos, que, mediante el estudio de su iconografía y morfología, pueden revelar las ideas imperantes de una época, el conocimiento de una determinada entidad geográfica, la percepción y definición mental respecto a ella, la sugestión del autor o lector del mapa (viajero, comerciante, erudito, navegante,

* Este proyecto forma parte del trabajo de fin de grado en Historia «La ordenación de un fondo de Cartografía inédito de la Real Sociedad Cosmológica de Santa Cruz de La Palma», presentado el 27 de marzo de 2019 a la Sección de Geografía e Historia de la Facultad de Humanidades de la Universidad de La Laguna.

** Graduado en Historia.

1 Thrower, Norman Joseph Wiliam: Mapas y Civilizaciones. Historia de la cartografia en su contexto cultural y social, Barcelona, Ediciones del Serbal, 2002, p. 11. 
geógrafo o cartógrafo), el afán por señalar o plantear algo o bien ocultarlo o deformarlo (manipulando intencionadamente la realidad), entre otras.

Según J.B. Harley, «la percepción común de la naturaleza de los mapas es que son una imagen, una representación gráfica de algún aspecto del mundo real $\aleph^{2}$; por lo tanto, «el papel del mapa es presentar una manifestación concreta de una realidad geográfica dentro de los límites de las técnicas de la topografía, de la habilidad del cartógrafo y del código de signos convencionales»" ${ }^{3}$.

En nuestra cultura occidental se ha definido la cartografía como una ciencia concreta en la que un mapa debe representar fielmente la realidad del momento plasmado. Esta percepción de la cartografía ha provocado que muchos historiadores releguen a un segundo plano mapas que no representan una realidad de manera adecuada. Se trata de un juicio de valores, probablemente involuntario, que limita la aportación de la cartografía a la historia. El resultado, como recoge Harley, es «... que cuando los historiadores hacen una valoración de los mapas, sus estrategias interpretativas son determinadas por esa idea de lo que se dice que son los mapas» ${ }^{4}$. Sin embargo, su estudio no solo nos ofrece la representación del mundo -correcta o incorrecta- en un momento determinado, sino que también es el constructo del pensamiento de una sociedad.

Un documento cartográfico puede ser apreciado además en una doble vertiente: como documento histórico y como elemento artístico. Como documento histórico, moderno o antiguo, es el resultado de una época y un momento determinado, siendo el reflejo del contexto histórico en el que fue elaborado. A lo que se puede añadir, si bien el mapa es una representación gráfica de un territorio, que es también un documento mediador entre un mundo físico representable empíricamente y uno mental, es decir, la plasmación mental de una realidad concebida a partir de un conjunto de experiencias y circunstancias propias de una época. Como diría Harley, «la fascinación que ejercen los mapas como documentos creados por el ser humano radica, no únicamente en la medida en que son objetivos o exactos, sino también en su ambivalencia inherente y en nuestra habilidad para encontrar nuevos significados, agendas ocultas y visiones del mundo opuestas entre las líneas de la imagen $»^{5}$.

La regla básica de la historia, que seńala que los documentos han de ser tratados en su contexto, debe ser extrapolada a los mapas, es decir, llevarlos de regreso al pasado y estudiarlos dentro de su propio tiempo y lugar. Así el mapa será el resultado de todo un conjunto de fuerzas interactivas que deben ser tratadas tanto individualmente como en su conjunto. Solo el estudio de los documentos cartográficos dentro de su contexto y de todos y cada uno de los elementos que influyeron en su resultado final permitirá su correcta interpretación histórica.

2 Harley, John Brian: «Hacia una deconstrucción del mapa», La nueva naturaleza de los mapas. Ensayos sobre la historia de la cartografía, Madrid, FCE, 2005, p. 60.

3 Idem.

${ }^{4}$ Idem.

5 Ibidem, 62. 
También es posible afirmar que los mapas son una compleja construcción social, en la que se halla un discurso oculto que lo sitúa en el contexto del poder político y de la cultura de la sociedad que lo produjo. Los mapas serían ricas fuentes de información del medio físico y geográfico, pero también el reflejo del contexto histórico-cultural en que se elaboraron.

El mapa es la representación de una realidad que ha surgido de la interacción social, donde es la política el elemento que articula estas relaciones. Aunque la ciencia sea capaz de representar la naturaleza de la manera más exacta posible, esa naturaleza que resulta plasmada va a estar condicionada por el contexto histórico y social en el que se percibió. Por tanto, el cartógrafo va a representar nuestra imagen del mundo, es el transmisor de un poder externo e interno, que es consecuencia de la interacción social del hombre. O en palabras de J.B. Harley:

Los mapas son imágenes acreditadas. Pueden reforzar y legitimar el statu quo, seamos o no conscientes de ello. Algunas veces son agentes del cambio y pueden de igual manera, convertirse en documentos conservadores. Sin embargo, en cualquier caso, el mapa nunca es neutral. Cuando parece serlo, la oblicua «retórica de la neutralidad» parece tratar de convencernos ${ }^{6}$.

\section{CANARIAS A TRAVÉS DE LA CARTOGRAFÍA}

Las islas Canarias han sido, a lo largo de la historia, un enclave fundamental para el desarrollo de los conocimientos y descubrimientos geográficos del hombre. Desde la Antigüedad clásica, tanto en el mundo grecolatino como en el fenicio -los dos grandes imperios de la época- concebían la costa occidental africana como la frontera de lo desconocido, es decir, tanto la historia como la cartografía van a estar imbuidas por un aura de mitología y desconocimiento. Aun así, con la duda razonable de su existencia, el archipiélago canario va a ser considerado como el fin (o el principio) del mundo, desde el inicio de nuestra era hasta el momento de los descubrimientos portugueses y españoles de las Indias occidentales.

Las primeras noticias ciertas que se tienen sobre la existencia de las islas Canarias provienen de los inicios de nuestra era, cuando Juba II, rey de Numidia, decide enviar una expedición en busca de las míticas islas Afortunadas, a partir de los conocimientos transmitidos por fuentes romanas como Estacio Seboso. Desafortunadamente, la relación original de estos textos se ha perdido y solo se conocen algunos extractos breves a través de Plinio el Viejo.

Ya en el siglo II d.C., Claudio Ptolomeo hace referencia a las islas Afortunadas en sus célebres tratados Geographike uphegesis y Megale sintaxis, recogiendo también las noticias de Juba II, aunque modificando los nombres de algunas islas. Ptolomeo reconoce seis islas en el archipiélago y las coloca alineadas de norte a sur.

${ }^{6}$ Ibidem, 103. 
La primera que describe es la que llama Aprositus Nesos, es decir, «isla a la que no se puede llegar", una isla inexistente que a través de los siglos ha cambiado su denominación hasta llegar al actual San Borondón, que en el s. XI se asociará al santo irlandés Brandan de Confert. La fantasía de una isla misteriosa, que aparece y desaparece, no es exclusiva de las islas Canarias ni de una época determinada; no obstante, la de San Borondón canaria, también llamada La Inaccesible, La Perdida o La Encantada, produjo, más allá de simples disquisiciones sobre su existencia, verdaderas expediciones de búsqueda. Además, Ptolomeo establece en este archipiélago el primer meridiano, considerando que señalaba el límite occidental de la tierra.

Los conocimientos geográficos sobre las islas Canarias se perderán durante varios siglos hasta la época musulmana. Sin embargo, algunos autores, desde Solino, en el siglo III, hasta san Isidoro de Sevilla, en el viI, hablan alguna vez de la posible existencia de unas islas atlánticas, con connotaciones mitológicas? ${ }^{7}$.

El personaje más representativo de estos mapas medievales será el monje español Beato, que en el siglo virI compuso unos Comentarios al Apocalipsis de San $J_{u a n}{ }^{8}$. En el ejemplar que se conserva en la Universidad de Valladolid -datado del año 970 - están dibujadas las tierras de un modo informe y equivocado, pese a que en el mar que rodea el mundo podemos reconocer las Fortunatas. Otro ejemplo, el de San Sever de 1070, muestra un gran avance de los cartógrafos españoles, apareciendo en la costa occidental de África dos archipiélagos, y se lee «Fortunata Y» en uno de ellos.

En lo que respecta a la cartografía referente a Canarias recogida del mundo árabe, hay que tener en cuenta que éstos llegaron a estar en contacto, al mismo tiempo, con griegos, godos, indios y chinos, captando la mayor parte de sus conocimientos científicos. Como ya se ha planteado, fueron los árabes los que se ocuparon de recuperar a los geógrafos y filósofos clásicos, algunos de los cuales debemos agradecerles que hayan llegado a nuestros días.

Entre las obras de geografía árabe en las que aparecen representadas las islas, cabe destacar la de Abu-Abdallah Mohamed el-Edrisi, en cuya obra, dividida por climas a la manera ptolemaica y dedicada al rey Rogerio de Hauteville, se recoge:

El primer clima comienza en la costa del oeste en el mar occidental llamado Mar de las Tinieblas. No se sabe qué hay más allá. Allí hay dos islas, llamadas Eternas (o Islas Afortunadas). Es desde estas islas desde donde Ptolomeo empieza a contar longitudes y latitudes? .

Otro ejemplo lo constituye la obra de Abulfeda de 1321, la cual no es más que una recopilación de noticias anteriores a él y de la obra del que se puede con-

7 Regueira Benítez, Luis: «Geografía y leyenda de las Islas Canarias en su cartografía antigua", Museo Canario, n. ${ }^{\circ}$ 53, 1998, p. 246.

${ }^{8}$ Realizado por Beato de Liébana tratando de explicar los hechos apocalípticos revelados por san Juan.

9 Regueira Benítez, Luis: «Geografía y leyenda de las Islas Canarias...», p. 250. 
siderar un predecesor suyo, Ibn Said. Ambos recogen la idea de un archipiélago, con seis islas deshabitadas, que se llaman islas Afortunadas. Después de Abulfeda, la cartografía árabe da paso rápidamente a la cartografía genovesa y mallorquina, ambas con muchos puntos en común.

El fin de la Edad Media se va a caracterizar por la aparición de las cartas náuticas, cuya diferencia con los mapas anteriores radica en que van a mostrar los vientos o rumbos, es decir, los caminos marítimos. A esto hay que añadir la aparición de nuevas técnicas de navegación, como la brújula y el astrolabio, que hicieron posible aventurarse mar adentro. Todo ello va a constituir el preludio de los descubrimientos portugueses y españoles, y más tarde de los ingleses y holandeses.

De las islas Canarias no se conoce ningún mapa náutico anterior al siglo XIII, y no es hasta el siglo XIV cuando aparecen imágenes fiables. De hecho, se puede establecer con cierta precisión el momento en el que las islas-redescubiertas en el 1336 o en los inicios de la centuria- quedan plasmadas por primera vez en documentos cartográficos, siendo en el año 1339 cuando se traza el portulano que verifica la reaparición de las islas en el mundo cartográfico. En éste, diseñado por Angelino Dulcert, aparece una ínsula con el nombre de Lanzarotus Marocelus (Lanzarote), otra denominada La forteventura (Fuerteventura) y un islote llamado Vegi Marini (Lobos) ${ }^{10}$.

Años después, en 1341, se inicia la expedición portuguesa liderada por un genovés, Nicoloso de Recco, que, según cuenta una carta de mercaderes florentinos establecidos en Sevilla y conservada en la Biblioteca Nazionale de Florencia, esta vez se recorre casi todo el archipiélago. Es seguro que visitaron Fuerteventura, Gran Canaria, El Hierro, La Gomera y La Palma, y posiblemente algunas de las islas Azores y Madeira ${ }^{11}$.

Después de este viaje y de algunos intentos mallorquines para visitarlas o conquistarlas, las islas Canarias se ponen de moda en Europa debido a su situación geográfica, y ya en el año 1351 encontramos un atlas genovés, el Atlas Mediceo-Laurentino o Laurentino-Gaddiano, en el que se pueden identificar la mayoría de las islas con las Canarias actuales, aunque también con elementos mitológicos como la isla de Brazi. Hay que decir, además, que por primera vez aparece la isla de Tenerife.

El siguiente mapa digno de mención es el de los hermanos Pizzigani de 1367, que se conserva en la Biblioteca Palatiana de Parma. Su importancia radica en que constituye el primer portulano en el que se muestran las siete islas de Canarias -la de El Hierro, aún sin nombre, ya que es la primera vez que aparece representada-. En este mapa se solapan ciencia y mitología, poniendo todo en un mismo plano, como resultado de un universo fantástico basado en las antiguas leyendas árabes y clásicas. No obstante, hay que decir, que su importancia va a quedar eclipsada por el que hoy se conoce como Atlas o Mapa Catalán de 1375, que, aunque no está firmado, no cabe duda (según los especialistas) de que es obra de Abraham Cresques.

10 Ibidem, 254. 
El atlas fue diseñado por encargo de Juan I de Aragón, que posteriormente se lo obsequiaría a Carlos V de Francia. En él aparecen las islas Azores, Madeira, Salvajes y Canarias, constituyendo todas ellas el límite occidental del mundo y que en conjunto se les llamará islas Bienaventuradas.

Con respecto a Canarias, en el Atlas Catalán se observan seis islas -La Palma no aparece representada-, así como algunos islotes. Además, aparece en rojo el nombre del archipiélago, que por vez primera es llamado Canaria, y una rosa de los vientos que pasa por el primer meridiano, el cual Cresques hace pasar una vez más por El Hierro, como hiciera Ptolomeo.

A partir del descubrimiento e incorporación de las islas a la corona castellana, se multiplican las representaciones gráficas sobre el archipiélago, como ha demostrado, entre otros, Tous Meliá en sus obras acerca de la cartografía en Canarias ${ }^{12}$.

\section{REAL SOCIEDAD COSMOLÓGICA DE SANTA CRUZ DE LA PALMA}

Una de las instituciones culturales más importantes de Canarias y una de las más veteranas en su actividad es la centenaria Sociedad Cosmológica de la Santa Cruz de La Palma.

Heredera del Siglo de las Luces y del valeroso esfuerzo de un grupo de ilustrados que sacudieron la sociedad y la cultura de su tiempo, fue fundada en enero de 1881 con la finalidad de instituir un Museo de Historia Natural y Etnográfico, para el estudio del medio natural y de la arqueología local.

Inaugurada en enero de 1887 , sus primeras instalaciones se ubicaron en la calle de la Cuna de la capital palmera -en unos locales cedidos por la Real Sociedad Económica Amigos del País-. Más tarde fue trasladada al edificio del antiguo pósito municipal de la calle Van de Walle, en la que hasta la fecha continúa ocupando la parte alta del inmueble ${ }^{13}$.

En sus inicios, y gracias a importantes donaciones y adquisiciones, pudo ofrecer al público una incipiente colección de ciencias naturales relativa al ámbito de Canarias, y en particular de La Palma -insectos, conchas, aves, minerales, etc.-, y también materiales benahoaritas resultantes de las excavaciones de cuevas aborígenes -utensilios, adornos, restos humanos, etc.-. La mayoría de estos objetos procedían de colecciones privadas.

Aunque la Sociedad Cosmológica nació como Museo de Ciencias Naturales, en su seno igualmente se gestaba la necesidad de crear una biblioteca que fomentara y extendiera la cultura en la isla. Para su creación fue determinante el apoyo

12 Obras como «Canarias a través de la cartografía: Una selección de los mapas emblemáticos levantados entre 1507 y 1898» o las dedicadas a Gran Canaria y Tenerife en particular.

${ }^{13}$ Aguilar Janeiro, María del Carmen: «La Sociedad «La Cosmológica» de Santa Cruz de La Palma: pasado, presente y futuro", Parabiblos: cuadernos de Biblioteconomía y Documentación, n. ${ }^{\text {os }}$ 5-6, 1991-1992, pp. 69-71. 
recibido de parte de D. Luis Vandewalle y Quintana, vi marqués de Guisla, quien realizó una importante donación de obras -1630 volúmenes- para impulsar dicho proyecto. Muestra que sirvió de acicate a otras personalidades que le siguieron con más donaciones para contribuir a conformar el fondo bibliográfico. De los más significativos podríamos citar a Juan Fernández Ferraz (intelectual), Pedro Poggio y Álvarez (político), Manuel Pérez Abreu (juez y notario), entre otros. Gracias a estos aportes y a la compra de ejemplares llevada a cabo por la propia institución, se constituyó una colección que dio inicio al cometido de la incipiente biblioteca.

En el año 1909 quedaba inaugurada oficialmente la Biblioteca Cervantes de esta Sociedad, en la que, por acuerdo establecido con el Ayuntamiento de Santa Cruz de La Palma, la consulta de sus fondos sería pública. Se cumplía así el anhelo de aquella comprometida intelectualidad de antaño, que no era otro que el de conservar la memoria de la sociedad palmera, difundir el conocimiento y que éste estuviese al alcance de todos.

Actualmente la Sociedad Cosmológica presta los servicios de biblioteca, archivo y hemeroteca. Las piezas y colecciones que otrora pertenecieron al Museo de Ciencias Naturales y Etnografía fueron cedidas en depósito - por falta de espacio en el inmueble- al Cabildo Insular, en el año 1983. Hoy estos fondos se encuentran formando parte del Museo de Insular de La Palma y del Museo Arqueológico Benahorita.

La Biblioteca Cervantes, en la actualidad, tiene carácter de biblioteca pública concertada y su fondo documental cuenta con más de 25000 volúmenes de todo tipo: literatura general, ciencias naturales, física, astronomía, náutica, derecho civil y canónico, medicina, etc. ${ }^{14}$.

Especial interés despierta su fondo antiguo impreso, en el que se conservan valiosas publicaciones comprendidas entre los años 1764 y 1950 -en su mayoría procedentes de los fondos de los conventos desamortizados en la isla-. La bibliotecaria e investigadora de esta institución, la Lcda. María del Carmen Aguilar Janeiro, lleva más de veinte años de estudio y catalogación de este fondo. Hay que destacar que, en su investigación de los volúmenes que se encontraban en los fondos descatalogados de la biblioteca, halló libros con 400 años de historia. Entre ellos destacan ediciones del siglo xvi de Las Siete Partidas - un cuerpo normativo redactado en la corona de Castilla, durante el reinado de Alfonso X--, o el diccionario de Nebrija latino-español. Merece mención especial entre las ediciones únicas encontradas el Índice de Libros Prohibidos por la Inquisición y el Santo Oficio, en su edición de 1747 -en palabras de la propia bibliotecaria- por la curiosidad que despierta en los visitantes de la Real Sociedad Cosmológica de Santa Cruz de La Palma. También

14 López Mederos, José Melquiades: «Sociedad la Cosmológica», Revista de estudios Generales de la Isla de La Palma, n. ${ }^{\circ}$ 0, 2004, p. 443. 
en esta biblioteca se encuentra el manuscrito original de la «Topografía de la isla Afortunada de Gran Canaria», obra de fray José de Sosa ${ }^{15}$.

La hemeroteca de esta Sociedad es una de las mejores de Canarias. Conserva toda la prensa periódica publicada en La Palma desde el ańo 1863, siendo su primer periódico el Time.

En lo que respecta a las series archivísticas, hay que hacer referencia a los legajos de las haciendas azucareras de Argual y Tazacorte, en la isla de La Palma, con documentación relativa a particiones, relaciones de bienes y sucesiones entre los propietarios de aquellos ingenios. Se conservan documentos desde los siglos $\mathrm{XVI}^{\mathrm{al}} \mathrm{xx}^{\mathrm{I6}}$.

La Real Sociedad Cosmológica también alberga una pequeña gliptoteca, en la que se custodian algunos blasones y escudos de antiguas familias de la ciudad, esculpidos en piedras para las fachadas de sus moradas. También conserva y exhibe los escudos de las antiguas fortalezas y portadas de acceso a Santa Cruz de La Palma. Ejemplo de este legado lo constituyen los blasones en piedra del primer adelantado, Alonso Fernández de Lugo, pertenecientes a la antigua torre de San Miguel del Puerto, su escudo real y también el de San Miguel Arcángel batiendo al dragón.

Por último, y no por ello menos importante, esta Sociedad conserva el Fondo Cartográfico que constituye el objeto de investigación de este trabajo.

Es bien sabido que la cultura es y será siempre creadora de identidad y en lo que respecta a la Sociedad Cosmológica -inicialmente Museo de Historia Natural y Etnográfico y más adelante biblioteca, hemeroteca y archivo-, ha demostrado desde su creación ser un agente dinamizador del desarrollo cultural de la sociedad palmera y una institución creadora de valores culturales, lo que la ha hecho merecedora de varias distinciones, como la Medalla de Oro de la Ciudad -concedida por el Ayuntamiento capitalino-, el premio José Pérez Vidal -del Cabildo Insular de La Palma-, la Medalla de Oro de Canarias - otorgada por el Gobierno de Canarias-y el título de real, ostentando S.M. el rey la presidencia de honor de la misma.

\section{EL FONDO CARTOGRÁFICO DE LA RSC ${ }^{17}$}

Durante siglos, solo algunas mentes preclaras y con visión de futuro intuyeron el verdadero valor del mapa; sin embargo, hoy día, los poderes públicos conocen de sobra el empuje y la fuerza que reviste la cartografía.

Es bien conocido en el campo de la investigación que la identificación y la individualización de un documento antiguo -cualquiera que sea éste- requiere de una labor ardua. En el caso de la cartografía es un tipo de documento complejo que

15 Ronquillo Rubio, Manuela y Viña Brito, Ana: «Fray José de Sosa. Topografía de la Isla Afortunada de Gran Canaria», Colecc. Insulas de la Fortuna, Las Palmas, Cabildo Insular G.C., Libro Primera parte, 1994.

${ }^{16}$ Cobiella Hernández, Manuel y Poggio Capote, Manuel: «La Real Sociedad Cosmológica de Santa Cruz de La Palma», Pecia Complutense, año 14, n. ${ }^{\circ} 26,2017$, pp. 17-41.

${ }_{17}$ RSC = Real Sociedad Cosmológica. 
se presenta en muy diferentes formatos y que emplea distintos tipos de lenguaje. Las normas de catalogación del Ministerio de Cultura de España lo incluyen entre los materiales especiales, ya que hay que emplear áreas específicas de descripción como la escala, el meridiano de referencia, las coordenadas, las dimensiones, etc.; además, su tipología es muy amplia, la temática o las materias son muy diversas y la responsabilidad de la obra es compartida - con frecuencia- por distintas personas que han desempeñado diferentes funciones en su elaboración.

El fondo cartográfico que nos ocupa en el presente trabajo pertenece a un fondo documental de la Real Sociedad Cosmológica de Santa Cruz La Palma -institución privada que presta servicios públicos-.

Con el objetivo de facilitar la consulta a los investigadores y acercar las colecciones a los ciudadanos, esta institución ha llevado a cabo a lo largo de los años una labor de análisis e investigación de los valiosos fondos que atesora, constituyendo uno de ellos el recientemente redescubierto fondo cartográfico.

Ya se ha apuntado que La Cosmológica-como se le conoce comúnmentepresta los servicios de biblioteca, hemeroteca y archivo. «Los especialistas definen archivo como una colección de documentos reunidos por una entidad en el ejercicio de una actividad práctica o necesaria ${ }^{18}$. Dicha reunión es impuesta por ley, ordenanza o necesidad de la entidad que la produce y esta necesidad hace que los documentos se reúnan seriada, continua y organizadamente porque la función archivística está, como las actuaciones que la originan, normalmente reglada ${ }^{19}$. Por lo tanto, podemos afirmar que los archivos promueven el conocimiento, custodian y preservan nuestra memoria, difunden nuestro patrimonio histórico, impulsan la investigación científica, apoyan la gestión documental de las organizaciones, entre otras funciones.

\subsection{El FONDO CARTOGRÁFICO Y SU ORDENACIÓN 4.1.1. Descubrimiento y tratamiento del fondo}

Este fondo de cartografía, recientemente redescubierto, va a estar conformado por una colección de mapas, planos y vistas de territorios relativos a diferentes regiones del mundo, debiéndose resaltar la escasa, confusa y fragmentada información que se posee con respecto a su origen o procedencia. A pesar de ello, nos hemos propuesto realizar, con todas las reservas, la ordenación y presentación de este valioso fondo cartográfico.

${ }^{18}$ Romero Tallafigo, Manuel: Archivistica y archivos. Soportes, edificios y organización, Asociación de Archiveros de Andalucía, Editorial S \& C, ediciones, 1994.

19 Cortés José, Joaquín: «La cartografía como patrimonio documental: Los mapas de Andalucía, noticias antiguas del territorio. Reconocimiento y evaluación de los archivos cartográficos con información sobre Andalucía", Revista ph. Instituto Andaluz del Patrimonio Histórico, n. ${ }^{\circ}$ 77, 2011, p. 14. 


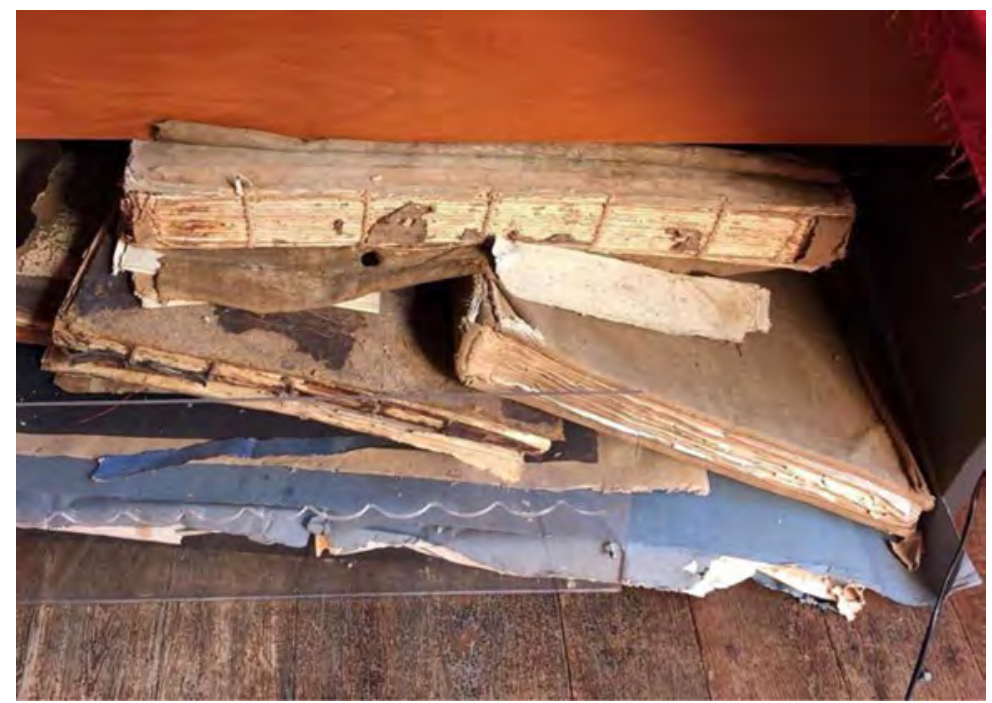

Fig. 1. Foto de las condiciones iniciales del fondo.

Es importante señalar que, al margen de un artículo publicado referente a la historia de esta institución -en el que se hace mención a un tratado perteneciente a este fondo $-{ }^{20}$, no se tiene constancia de ningún trabajo de investigación publicado referente a los documentos que conforman este fondo cartográfico; por lo tanto, se trata de un fondo de carácter inédito.

La reciente reaparición de este fondo cartográfico se la debemos a la bibliotecaria e investigadora de la Real Sociedad Cosmológica, la Lcda. María del Carmen Aguilar Janeiro, y fue localizado en el año 2014, dentro de una caja situada en una de las estanterías de la primera planta de esta Sociedad (fig. 1).

Este fondo había permanecido cerrado durante un largo período de tiempo y tras su primera manipulación, la citada bibliotecaria sufrió un contagio (vía aérea) de una bacteria. Este incidente provocó que se paralizara la labor de investigación del fondo durante cuatro años, pudiéndose reanudar en el momento en que se nos permitió realizar el presente trabajo de organización.

Cuando se nos mostró el fondo sus documentos se hallaban apilados en la segunda planta del inmueble que ocupa la Real Sociedad Cosmológica, carentes de ordenación y en «depósitos» inadecuados. Esto se debe a que este organismo carece de personal especializado para llevar a cabo una adecuada labor técnica de custodia

${ }^{20}$ Cobiella Hernández, Manuel y Poggio Capote, Manuel: «La Real Sociedad cosmológica...", p. 28. 


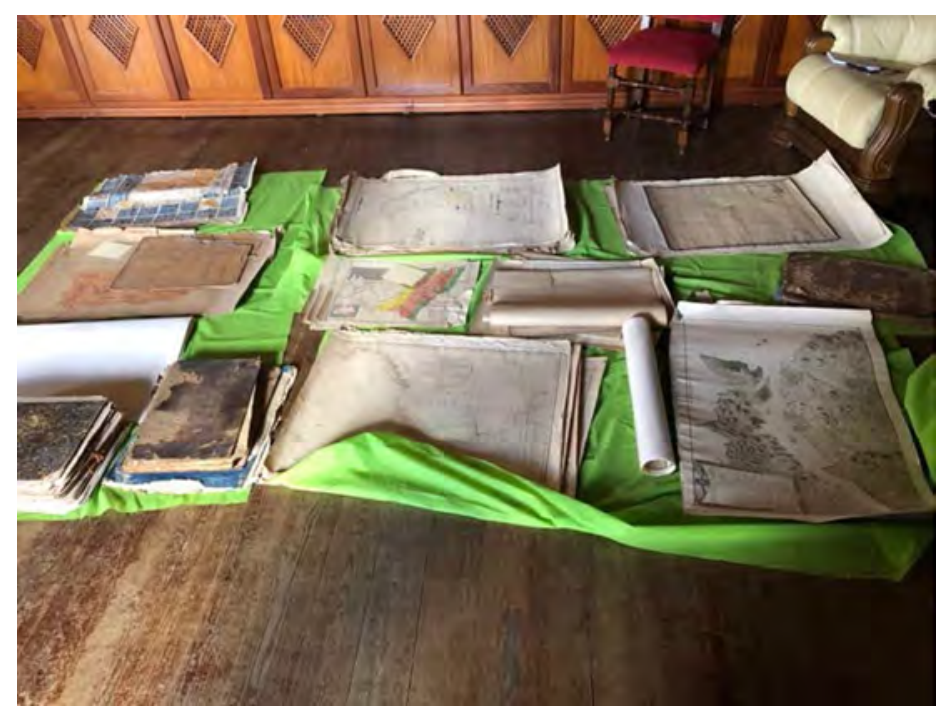

Fig. 2. Foto realizada tras la limpieza y ordenación del fondo.

y conservación de cartografía, así como a la falta de recursos y de espacio que presenta la institución. Hay que añadir, además, que, en algunos casos, el mal estado que presentaban algunos mapas guarda una estrecha relación con las características físicas del documento (dimensiones, tipo de material, etc.), que han dificultado su almacenamiento y han acabado ocupando lugares menos accesibles y adecuados para su correcta conservación. Como resultado, este fondo presentaba signos visibles de humedad provocada por factores externos, como fue una inundación que sufrió el inmueble y que trajo como consecuencia el traslado temporal de sus fondos. También se encontraba afectado por agentes biológicos que comúnmente atacan los materiales impresos, como es el caso de insectos y orina de roedores.

Cabe destacar que los documentos impresos son una fuente nutricional para diferentes organismos y microorganismos, no solo por la naturaleza constitutiva de su soporte de información -el papel- sino también por todos los compuestos orgánicos que intervienen en su manufactura como las tintas, colas vegetales y animales y materiales de encuadernación como cartones, cueros y telas.

La colección con que cuenta el fondo la conforman un total de cinco libros y más de 70 hojas cartográficas que datan de finales del siglo XviII a mediados del xx y han sido agrupadas atendiendo a su temática, las instituciones y autores que la elaboraron, los marcos temporales a los que pertenece, la descripción espacial, etc.

Durante los cuatro meses de trabajo en el fondo cartográfico -labor de limpieza, análisis y organización - fueron superadas todas las expectativas en cuanto al número posible de mapas existentes, desvelándose un copioso patrimonio documental con una amplia diversidad temática (fig. 2). 


\subsubsection{Origen y procedencia}

En las instituciones que cuentan con mucho tiempo de antigüedad -como la que nos ocupa- sus fondos antiguos se han ido conformando gracias a la adquisición de documentos por planes de compras propios o por adquisición de bibliotecas privadas, así como también por donaciones de instituciones, o procedentes de colecciones privadas, desamortizaciones, etc., de ahí que reúnan un conjunto documental muy diverso, como pueden ser manuscritos -originales y copias-, publicaciones impresas, recortes de prensa, carteles, fotografías, dosieres temáticos, etc.

En el caso de la Real Sociedad Cosmológica hay que decir que no se puede establecer con seguridad la procedencia de los documentos que conforman este fondo. Esto se debe a que no existe ningún tipo de documentación que haga referencia a su origen, ni al momento en que llegó a la institución. Únicamente conocemos la procedencia de una obra, The Modern System of Naval Arquitecture, la cual fue donada por un sobrino de D. Gabriel Duque Acosta, en el ańo 1986, al entonces presidente de la Sociedad, D. Facundo Daranas Ventura.

La escasa documentación existente relativa a este fondo cartográfico -solo un pequeño e improvisado inventario- nos ha limitado las fuentes de información, teniendo que recurrir exclusivamente a las fuentes orales. De ahí que se intentara, a través de los técnicos de la biblioteca o personas que en algún momento formaron parte de la institución, recabar toda la información posible acerca del origen del fondo documental ${ }^{21}$. Pese a ello, no tener constancia, ni siquiera, de cuándo llegó esta documentación a la institución nos imposibilita establecer, con algún rigor, sus orígenes o procedencia.

Aun así, hemos barajado varias hipótesis sobre el posible origen de los documentos: las donaciones realizadas por D. Luis Vandewalle y Quintana, vi marqués de Guisla; las de la familia Arozena; los fondos procedentes de los conventos desamortizados; o que pudieran pertenecer a algún alto cargo de la marina por las características militares de los documentos. Otra teoría es que pudo haber pertenecido a algún militar, posiblemente originario de la isla, que se trasladó a América y a su regreso trajo consigo esta documentación. Esto tiene que ver con la inscripción hallada en el English Pilot: the fourth book, en la que aparece recogido el nombre de José Benito Luxán, capitán de Artillería de las Milicias de La Palma, quien probablemente habría adquirido este libro en Campeche, México, en el año 1754 -fecha recogida en el documento-. Además, hemos podido comprobar que este personaje envió un exvoto marino al santuario de Las Nieves.

Sin embargo, las fuentes orales coinciden en la hipótesis de que el origen de los documentos que conforman el fondo podría estar relacionado con la designación y nombramiento de corresponsales - muchos de ellos marinos- llevado a cabo desde la propia fundación de la Sociedad. Esta designación no solo se realizó a nivel insular y de Canarias, sino también nacional (Madrid, Sevilla, Granada, etc.) e inter-

${ }^{21}$ Entrevista con Manuel Garrido Abolafia, expresidente de la Real Sociedad Cosmológica. 
nacional (Francia, Portugal, América Latina, etc.). Que como recoge J. Melquiades: «Fueron eficaces las corresponsalías, lo que ha devenido en importantes, variados y, a veces raros, tanto objetos para su Museo de Historia Natural y Etnográfico como documentos impresos y libros ${ }^{22}$.

\subsubsection{Metodología}

El objetivo fundamental de este trabajo es dar a conocer la existencia de un fondo inédito de cartografía en la Real Sociedad Cosmológica de Santa Cruz de La Palma, que no son habituales, y sobre todo en una institución privada.

Como ya hemos apuntado, los documentos que conformaban este fondo cartográfico se encontraban apilados y sin ninguna ordenación. Además, contenía documentación referente a otras temáticas, como cartelería, fotos, grabados, dibujos a carboncillo, etc., que no serán tratados en este proyecto.

Hay que tener en cuenta que los documentos de archivos requieren de cuidados especiales, tanto de preservación del material como de protección para el personal que participa en su manipulación. En nuestro caso, se ha tenido especial cuidado en cumplir las normas básicas acerca de la manipulación de archivos, como la utilización de guantes y mascarilla para evitar que estas tareas se conviertan en un factor de riesgo para la salud.

También constituyó un imperativo que el manejo de los documentos se realizara con la mayor delicadeza posible, máxime cuando se trataba de ejemplares con varios siglos de antigüedad y algunos presentaban signos importantes de deterioro. Hay que decir que una manipulación incorrecta podría conducir a daños serios e irreparables.

Los criterios tenidos en cuenta para la organización del fondo han sido: colocar los documentos, de los más antiguos a los más modernos, de los cartógrafos que los levantaron a los organismos productores, por su técnica de elaboración, así como por la información de sus leyendas.

Para comenzar la labor de organización del fondo fue necesario llevar a cabo un estudio de la institución que lo custodia, en este caso, la Real Sociedad Cosmológica, para conocer el ejercicio de sus funciones, actividades, procedimientos, así como sus formas de organización documental. Se indagó sobre las procedencias de sus fondos y se llevó a cabo un análisis de la evolución histórica de la institución con el fin de realizar una investigación sobre su fundación, crecimiento y desarrollo. Y ya por último, se procedió a realizar una organización del fondo documental, que incluía las labores de limpieza y ordenación del fondo.

Evidentemente, esta labor no ha estado exenta de dificultades. Las principales fueron la antigüedad de la institución, su complejidad institucional, la fragmentada y dispersa documentación sobre cartografía, la falta de catálogos, inven-

22 López Mederos, José Melquiades: «Sociedad La Cosmológica», p. 441. 
tarios o índices sobre los mapas, la inexistencia de información acerca del origen y procedencia de los fondos cartográficos, pero, sobre todo, el hecho de que se trate de un conjunto documental recientemente redescubierto e inédito de cuya catalogación solo tenemos un improvisado inventario de algunos mapas.

\subsubsection{Fases del trabajo}

Para la observación y el análisis del material documental hallado en este fondo, nos hemos apoyado en algunos elementos cartográficos que ayudan a leer e interpretar el mapa con mayor facilidad, como son la existencia de títulos o texto explicativo que nos describen el propósito del mapa -aunque el título del documento no sería suficiente para determinar la materia- y también las referencias o leyendas, que describen los símbolos usados para representar los elementos geográficos. También hemos analizado las distintas instituciones productoras, así como los autores que levantaron los mapas.

Atendiendo a estos criterios de análisis e investigación podemos definir tres fases. Una primera fase de análisis histórico del período en el que se engloban la mayor parte de los documentos cartográficos hallados -los años 1787-1950-. Aunque existen algunos mapas que podrían pertenecer a períodos anteriores, no se ha podido determinar la fecha exacta.

Ya establecido el marco temporal, se procedió al estudio de la evolución cartográfica entre los siglos XVI, XVII, XVIII, XIX y XX, ya que, aunque la mayor parte del fondo tiene como organismo productor el Depósito Hidrográfico de Madrid, también cuenta con mapas procedentes de diferentes regiones y en otros idiomas.

Una segunda fase estuvo dedicada al análisis de las diferentes temáticas de los mapas, de las instituciones productoras, de sus autores, de las técnicas empleadas en su elaboración, etc. Para ello, y ante el desconocimiento en los primeros momentos de lo que podría ser el fondo, nos pusimos en contacto con doña Carmen Manso Porto (doctora en Historia del Arte y una de las principales especialistas en cartografía), quien nos indicó todo un conjunto de recursos bibliográficos y cartotecas con las que encaminar nuestra labor de investigación.

Y una última fase, en la que, a partir de toda la información extraída del material cartográfico estudiado y de los criterios de organización tenidos en cuenta, se intentó establecer una relación lógica y una coherencia entre los distintos elementos para lograr así la ordenación del fondo.

\subsubsection{Ordenación del fondo cartográfico}

Los mapas impresos suelen ser, por lo general, los más conocidos en el mundo de la cartografía: se encuentran citados en numerosas obras de referencia, se conocen sus autores, editores/impresores, el número de ejemplares, los estados, etc. Los primeros mapas impresos en Europa datan del siglo $\mathrm{xv}$-los más antiguos proceden de China, grabados por Lui Ching Zu, en 1155-. A partir de la segunda mitad del 
siglo xvi comienza la edición impresa de atlas, y con ello aumentó considerablemente el número de editores europeos.

La cartografía contenida en este fondo se presentaba fundamentalmente impresa, en forma de libros, atlas, colecciones y mapas sueltos -en gran formato, formatos menores y plegados- siendo su origen inglés, francés y español. Asimismo, también contenía mapas manuscritos como el del puerto de La Habana, el cual no se ha podido datar debido a las malas condiciones de conservación. De ahí, la dificultad que supone a la hora de establecer la autoría de un mapa manuscrito, que su estado de conservación no sea el correcto.

Es de señalar que el gran número de mapas de origen francés e inglés que contiene este fondo se debe fundamentalmente a que se encuentran formando parte de los tres volúmenes de la Marina Francesa y a las dos copias del English pilot: the fourth book. También varios mapas sueltos como La Carta Itineraria de los Reinos de España de Hérisson o la Tableau Comparatif de la hateur des montagnes, que forma parte del Atlas clásico de C.V. Monin.

Asimismo, el fondo contaba con una copiosa cartografía española comprendida entre los siglos XVIII-XX, debiendo destacarse la producida por el Depósito Hidrográfico (o Dirección de Hidrografía de Madrid) y en especial la realizada por José de Espinosa y Tello y Vicente Tofiño de San Miguel. De este último podemos plantear que probablemente los mapas producidos por él hallados en este fondo podrían pertenecer a su Atlas Marítimo de España de 1789 y al Portulano de las costas de la Península de España, Islas adyacentes y parte de la costa de África, ya del año 1813, obras cumbres de la cartografía española.

Es importante señalar que la cartografía institucional promovida por los Estados no va a aparecer hasta el siglo XVIII, aunque se pueda encontrar algún mapa nacional a finales del siglo Xvir y también algunos proyectos que no se llevaron a cabo. Ya desde inicios de la centuria, el saber cartográfico se vio fortalecido con la llegada de la nueva dinastía borbónica, que comprendió la necesidad de una política naval más activa y que por ello dio nuevos aires a la construcción naval y a la industria militar para poder mantener las pretensiones en el Mediterráneo, Atlántico y Pacífico. Así, los avances potenciaron la navegación y consecuentemente la cartografía a través de nuevas cartas náuticas. A lo largo del siglo aparecieron novedosas instituciones creadas bajo los auspicios y el interés de la corona como la Academia de Guardia Marinas (1717), el Real Observatorio Astronómico (1753), el Depósito Hidrográfico (1770) y luego la Dirección de Hidrografía $(1797)^{23}$. De ahí la importancia de resaltar la aparición de mapas y colecciones como los de Espinosa o Vicente Tofiño, a raíz de los descubrimientos y conquistas de los territorios de Ultramar.

Y, por último, la cartografía militar también hallada en este fondo que data del siglo XIX y que pertenece al Depósito de la Guerra, así como también mapas

${ }^{23}$ Moreno Gallego, Valentín: «Corona y cartografía: la colección de la Real Biblioteca», Reales sitios: revista de Patrimonio Nacional, n. ${ }^{\circ} 48,2011$, p. 8. 
físico-políticos como la Carta general de obras públicas de España formada por el cuerpo de ingenieros de caminos y canales de 1882 .

Tras un estudio detallado de los mapas y con el objetivo de lograr una mejor comprensión de los documentos que conforman este fondo cartográfico, decidimos distribuirlos en tres grupos. Un primer grupo que incluye un conjunto de libros: dos volúmenes de la Marina Francesa, tres volúmenes de Arquitectura Naval, dos ejemplares del English Pilot: the fourth book -uno casi completo y del otro solo se conservan dos páginas- y un ejemplar del Atlas Histórico, Genealógico, Cronológico, etc., de Lesage. Un segundo grupo conformado por varias colecciones: una perteneciente al Depósito Hidrográfico (o Dirección Hidrográfica de Madrid), un conjunto de copias del Agricultural Maps of the New South Wales y un conjunto de mapas físico-políticos y Teatros de la Guerra. Por último, un tercer grupo que aglutina mapas que destacan por su relevancia o por hacer referencia a contextos específicos: un Boletín de Tabacos y Timbres de 1887, un mapa manuscrito coloreado del puerto y la topografía de la ciudad de La Habana, varios mapas de la isla de La Palma o un mapa referente a la epidemia de peste de Santa Cruz de Tenerife (1906-1907).

\section{RELACIÓN DE DOCUMENTOS}

\subsection{LiBros}

\subsubsection{Volúmenes I y II de la Marina Francesa}

Se trata de un atlas general conformado por dos volúmenes pertenecientes al Depósito General de la Marina francesa. Se presentan encuadernados en tapa dura de color marrón claro, en buen estado de conservación y realizados en francés.

El Dépòt de la Marine, conocido formalmente como Dépòt des cartes et plans de la Marine, fue la principal institución de cartografía de Francia. La centralización de la hidrografía en Francia comenzó con el nombramiento de Jean-Baptiste Colbert como primer ministro en el año 1661 y la creación de la Real Escuela de Hidrografía. A partir del año 1773, el Dépòt se va a convertir en el principal productor de cartas náuticas de Francia, en el cual trabajarán cartógrafos de renombre como Philippe Bauche o Jacques-Nicolas Bellin.

\subsubsection{The Modern System of Naval Architecture by J. Scott Russell. FRS}

El sistema moderno de arquitectura naval -que forma parte de este fondo documental- constituye un Tratado de arquitectura naval publicado en Londres en el año 1865 por mapmaker Day and Son. Se presenta en tres volúmenes de tapa dura, elaborados en cuero de color verde y rojo con letras doradas. El papel utilizado es grueso -medidas aproximadas $52 \times 70 \mathrm{~cm}$ - y se encuentra en buen estado de conservación. El idioma utilizado es el inglés. Hasta el momento no se han encontrado copias en las cartotecas digitales de España (fig. 3). 


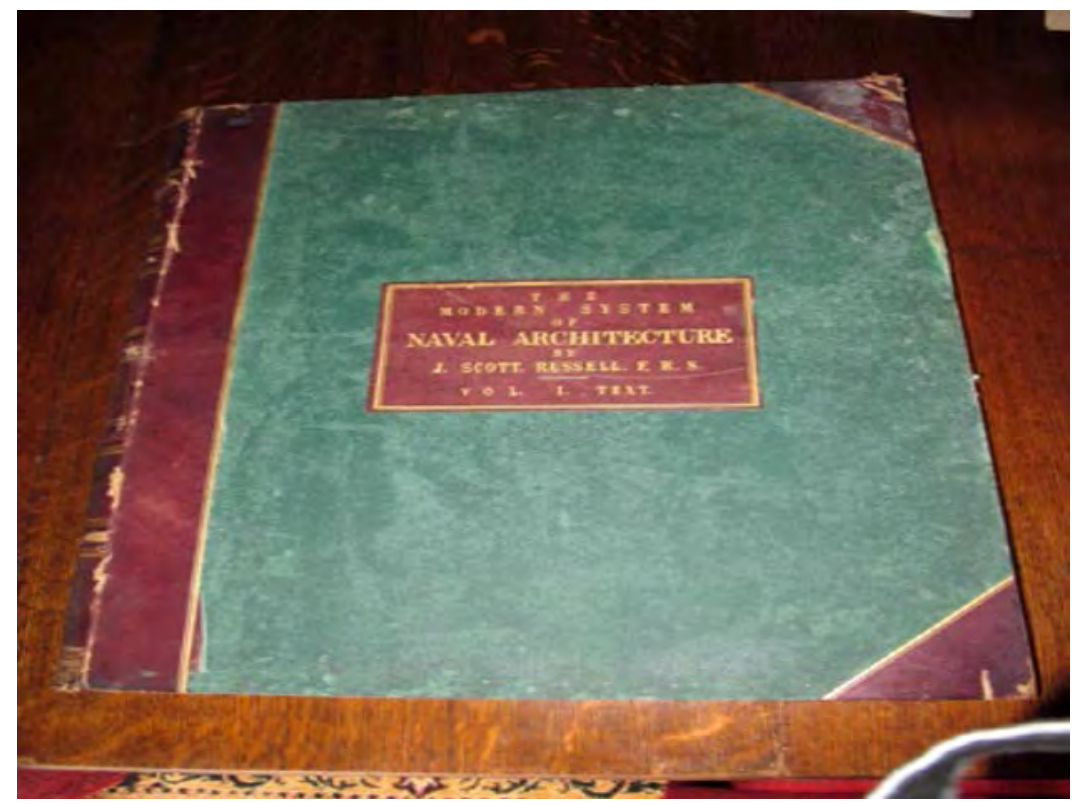

Fig. 3. The Modern System of Naval Architecture de Scott Russell.

Su autor, John Scott Russell, fue un ingeniero civil escocés, arquitecto y constructor naval, cuya mayor contribución a la ciencia fue el extraordinario descubrimiento de la onda de transmisión u onda solitaria -también llamada solitón-. El primero en observarla fue Scott Russel al estudiar la propagación de ondas acuáticas en canales poco profundos. Para su sorpresa, la onda producida de la detención brusca de una barcaza tirada por dos caballos a ambos extremos del canal era de gran altura, bien diferenciable y no parecía debilitarse, es decir, aparentemente no variaban su forma ni su velocidad. Sus ideas fueron poco comprendidas por sus contemporáneos, y no fue hasta la década de 1960 cuando la importancia de su hallazgo fue plenamente apreciada. Se descubrió que muchos fenómenos en la física, la electrónica y la biología pueden describirse mediante una teoría matemática y física de «Solitón», tal como se conoce ahora la ola de Scott Russell.

Scott Russell nunca abandonó el tema de las olas solitarias, sino que utilizó su investigación para desarrollar la línea de onda, un sistema de construcción de cascos de barcos -compilados en los tres volúmenes de este Tratado- que revolucionó la arquitectura naval en el s. xix y por el que se le otorgó la medalla de oro de la Sociedad Real de Edimburgo en 1837. Con esta teoría intentaba resolver el problema fundamental en el diseño de barcos: una forma de casco que ofreciera la menor resistencia, moviendo la masa de agua de la manera más eficiente posible.

The Modern System incluye placas detalladas de monitores, torretas giratorias estadounidenses, yates, un barco de vapor de río, comerciante, pasajero y embarca- 
ciones navales estadounidenses, un Pacific Mail Steamer, cinco placas de un vapor de hierro australiano con tornillo y 22 placas detalladas del Great Estern. Es, posiblemente, el trabajo más importante sobre arquitectura naval de su tiempo.

Con la colaboración de Isambard Kingdom Brunel, construyó el Great Eastern (1854-57; lanzado en 1858), el buque más grande de su época y el primero en tener un doble fondo celular, doble cubierta superior celular y mamparos longitudinales. En resumen, el primer barco de hierro construido. El barco encarna la forma de línea de onda, el sistema longitudinal de construcción, los mamparos completos y parciales, y otros detalles de construcción que fueron peculiarmente de Scott Russell.

George Emmerson, su biógrafo, se refiere al The Modern System como «un gran Este de libros». «Sin duda, el tamaño de los volúmenes fue dictado por la gran escala de los muchos dibujos... Es un monumento al dominio de Russell sobre su tema, su originalidad y su capacidad como maestro, una verdadera Biblia para los arquitectos navales de su tiempo». Hay que decir que The Modern System of Naval Architecture constituyó la obra maestra de Russell: una guía completa para el diseño y la construcción de barcos de vapor de hierro.

\subsubsection{English Pilot: the fourth book}

En este fondo documental de la Real Sociedad Cosmológica se encuentran dos copias del English Pilot: the fourth book: atlas de origen inglés que describe la navegación de las Indias occidentales, desde la bahía de Hudson al río Amazonas. Se trata de dos ediciones publicadas en Londres por William Mount and Thomas Page en Tower-Hill y presentados en tapa dura de color marrón, en soporte papel, con unas dimensiones aproximadas de $48 \times 60 \mathrm{~cm}$ y en diferentes estados de conservación.

La primera de estas ediciones data de 1751 (fig. 4) y se conserva casi en su totalidad. En su primera página aparece referenciado: «Campeche, año 1754, José Benito Luxán».

Se ha podido constatar que Benito Luxán fue un capitán de Artillería en las Milicias de La Palma, habiendo contraído matrimonio en Santa Cruz de La Palma con doña María Margarita de Carta y Gutiérrez de Abreu en la iglesia de El Salvador el 9 de enero de 1746. Probablemente Benito Luxán habría adquirido este libro en el año 1754 en Campeche, México. De este personaje hemos podido comprobar que envió un exvoto marino que, como recoge José Concepción: «... Uno de estos se ubica en el santuario de Las Nieves, y se refiere a la salida de La Habana, el tres de agosto de 1757, del navío "Nuestra Señora de las Angustias", "alias el Canario".... ${ }^{24}$.

24 Concepción Rodríguez, José: «Exvotos pintados en Canarias», IX Coloquio de Historia Canario-Americana, tomo II, Casa de Colón, Cabildo de Gran Canaria, 1990, p. 1365. 


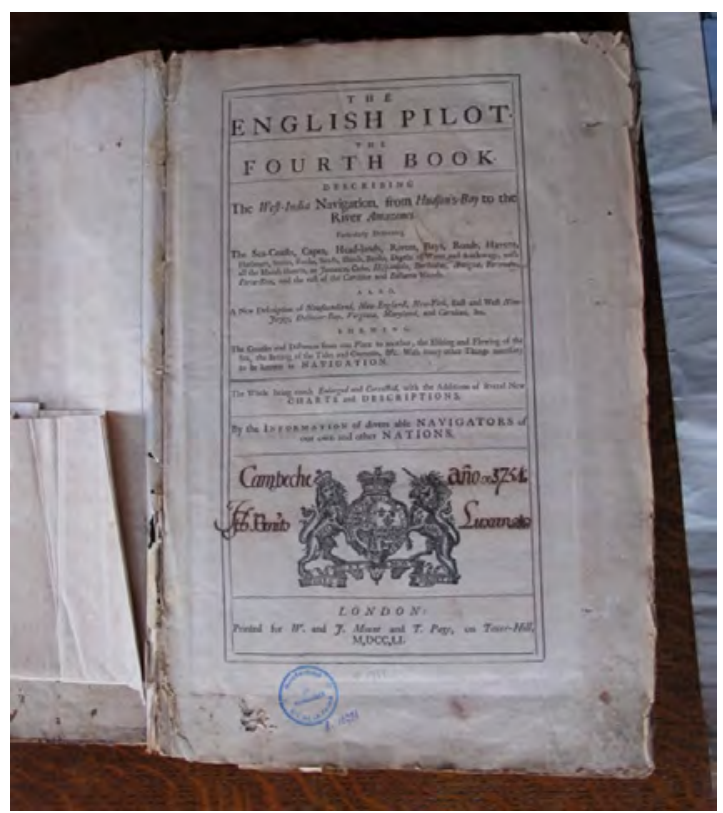

Fig. 4. English Pilot: the fourt book. Edición de 1751.

De este exvoto -pintura sobre tabla $(51 \times 70 \mathrm{~cm})$ - debemos destacar el detalle de su leyenda:

Habiendo salido para las Canarias de la Habana el 9 de agosto del año 57 el navío nombrado Nra. Sra. de las Angustias (a) el Canario su Capitan Dn. Franco. Cousel, desembocó con felicidad y estando en altura de $36^{\circ} 8^{\prime}$ y en longd. de $31^{\circ} 43^{\prime}$. le sobrevino un huracan y corrió 24 horas. pero habiendo invocado a Nra. Sra. de las Niebes cesó la tempestad. Hisose este diseño pr. devocon. del Capn. y Dn. Jose Benito Luxan Piloto de dha. Embarcación.

También, en el reverso de esta primera página, aparece estampada la firma de Charles Kennoway. De este personaje no se ha podido recabar información.

La segunda edición encontrada en este fondo data de 1716, pero lamentablemente solo se conservan la portada y la introducción.

Hay que destacar que el «Piloto Inglés» lo componen una serie de volúmenes con instrucciones de navegación iniciados en 1671 por John Seller y basados en los trabajos del piloto holandés Pieter Goos. La serie consistía en «libros» numerados ordinariamente, es decir, volúmenes independientes que describían diferentes regiones geográficas, convirtiéndose en el primer atlas marino verdaderamente importante publicado en Inglaterra y que puso fin al predominio holandés. El English Pilot, en su conjunto, tuvo una larga y compleja historia editorial que ilustra el desarrollo del comercio de cartas en Inglaterra. 
The English Pilot: the fourth book se publicó por primera vez en Londres, siendo anónimo e iniciado como parte de la serie de libros de navegación costera de John Seller -editor de obras de navegación- y completado por William Fisher y John Thornton -cartógrafo y grabador de mapas-, convirtiéndose en el más exitoso de los cinco volúmenes. Tras la muerte de Fisher en 1691, Thornton se asociará con Richard Mount para producir ediciones posteriores en 1698 y 1706. A partir de 1707, Mount continuará publicando diferentes ediciones con Thomas Page, a las que siguieron las de sus descendientes hasta el año 1794. La demanda fue tan importante que se publicaron 37 ediciones entre 1689 y 1794, además de tres ediciones "piratas».

La producción final del cuarto libro fue el resultado de una combinación afortunada que incluyó una empresa de producción de mapas exitosa, con una tienda y capital adecuado para producir la impresión tipográfica, y un cartógrafo y grabador igualmente exitoso que produjo gran parte de la obra cartográfica más refinada hecha en Inglaterra durante esta época.

\subsubsection{Atlas Histórico, Genealógico, Cronológico, etc., de Lesage}

El Atlas Histórico, Genealógico, Cronológico, etc., de Lesage que encontramos en este fondo lo comprenden 35 cuadros sinópticos, acompañados de amplias explicaciones de la historia universal, algunos de los cuales insertan mapas ilustrativos de textos. Se trata, en su mayoría, de mapas generales de los continentes o de países europeos, incluyendo también varios mapas relativos a la historia de éstos, como la formación de los actuales estados, así como algunos mapas de historia antigua.

Este atlas fue publicado por la librería Hispano-Francesa de Bossange Padre, en Francia, en el año 1826, siendo su autor el conde de las Casas, impreso por Firmín Didot y traducido, corregido y aumentado por D. Andrés Arango, el cual aparece citado como «un español americano».

Para la elaboración de este atlas se utilizó papel grueso -medidas aproximadas de $55 \times 36 \mathrm{~cm}-$. Su estado de conservación es bueno, aunque con restos de humedad, y su encuadernación - de tipo holandesa con lomo de piel- se halla muy deteriorada, con muestras de rotura. Presenta una portada tipográfica, decorada con la que podría ser la marca del editor (fragmento de columna rodeado por objetos alusivos al comercio, la cartografía y las bellas artes, bajo el lema: «La Historia es la antorcha de la verdad»). Además, el verso que ocupa la anteportada refleja una relación de las diferentes ciudades en las que podía encontrarse la obra.

Se conoce que la obra francesa fue publicada por primera vez en París en 1803/1804 bajo la autoría de A. Lesage, reimpresa con el nombre de conde de Las Casas, considerado su verdadero autor (entendiéndose que la palabra «Lesage» era solo un pseudónimo). Según Quérard en su obra «France Littéraire», el nombre de Lesage no sería un pseudónimo del conde de Las Casas, sino el nombre de un clérigo francés refugiado en Inglaterra o de un clérigo irlandés. Sería uno de estos eclesiásticos quien propondría al conde la venta de su manuscrito por el precio de mil 
francos ${ }^{25}$. No obstante, la traducción de Andrés Arango -la cual encontramos en este fondo- empezó a publicarse en 1826 y terminó en 1827, enviándose casi en su totalidad a América.

Aunque la traducción castellana no se hizo teniendo en cuenta las modificaciones introducidas en las numerosas ediciones francesas que siguieron a la de 1803; el traductor, por su parte, reformó parcialmente el libro, suprimió o abrevió algunos cuadros y noticias que no tenían gran interés para América, amplió las que se referían a España y América en general y agregó cuatro grandes cuadros impresos en los que se describe la historia de las repúblicas y colonias americanas.

Teniendo en cuenta el momento en que se publicó este atlas y la escasez relativa de libros sobre esta temática, estos trabajos son notables por la exactitud de las noticias, por la claridad con que están presentadas y por el plan que ha permitido al autor formar un compendio de la historia americana ${ }^{26}$.

\subsection{Colecciones}

\subsubsection{Colección del Depósito Hidrográfico o Dirección de Hidrografía (actualmente Instituto Hidrográfico de la Marina)}

Gran parte de los documentos hallados en el fondo cartográfico de la Real Sociedad Cosmológica de Santa Cruz de La Palma corresponden a mapas procedentes del Depósito Hidrográfico. Se ha podido establecer que al menos 34 de los mapas encontrados fueron producidos por dicha institución, en el período de tiempo comprendido entre los años 1787 y 1857 , ya que muchos de ellos presentan un sello identitario del Depósito Hidrográfico o porque sus creadores pertenecieron a dicho Depósito. En estos mapas aparecen representados diferentes territorios pertenecientes a la corona -desde el litoral peninsular a los de Ultramar-, así como varios mapas en los que se representan las islas Canarias.

Es loable destacar que, formando parte de este fondo cartográfico, se encuentran mapas elaborados por figuras excepcionales dentro del panorama científico español, como Vicente Tofińo de San Miguel -brigadier de la Armada, cartógrafo y marino- y un innovador de la cartografía mundial. También de la talla de José de Espinosa y Tello (fig. 5), teniente general y primer director del Depósito Hidrográfico, o José Varela y Ulloa -brigadier de la Armada- con su valiosa descripción de las islas Canarias en su famoso Derrotero: obra de gran valor histórico para Canarias, que recoge aspectos administrativos, sociales, económicos y demográficos. Todos ellos formarían parte de la comisión liderada por Vicente Tofiño, que publicaría en 1789 el Atlas Marítimo de España -obra cumbre de la cartografía española-, para el que se habían introducido y utilizado métodos geodésicos e hidrográficos, consi-

\footnotetext{
${ }_{25}$ Anales de la Universidad de Chile: Memorias Cientificas i Literarias, $1 .^{a}$ sección, tomo LXI, Imprenta Nacional, Bandera, n. ${ }^{\circ}$ 29, 1882, p. 22.

${ }^{26}$ Ibidem, 22-23.
} 


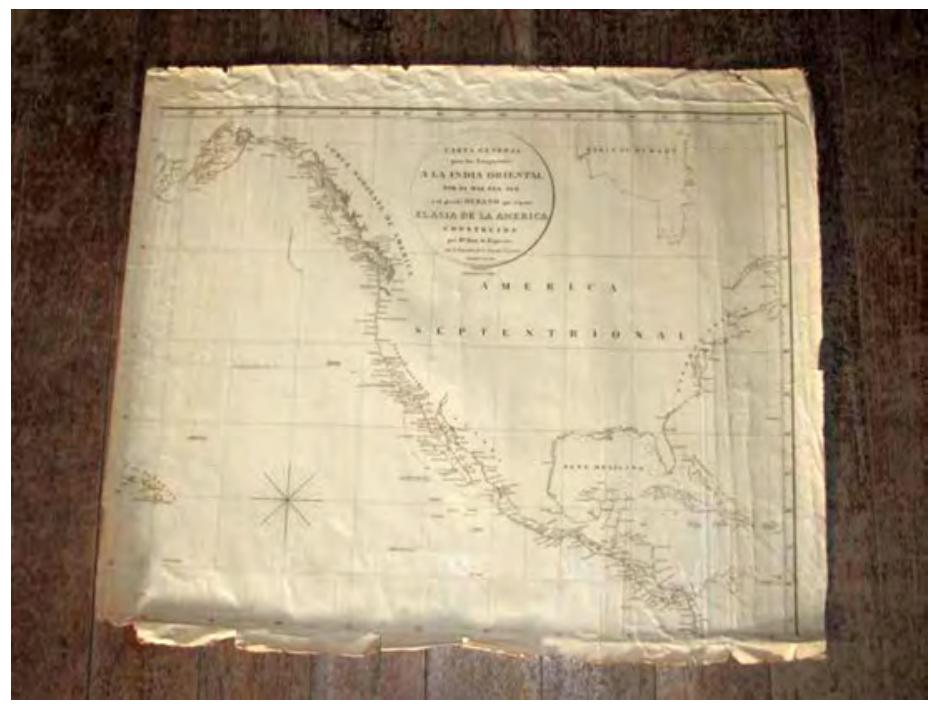

Fig. 5. Mapa de José de Espinosa y Tello.

guiéndose un mapa científico de las costas de España (equivalente a los mejores de su época) que contrastaba con los métodos de gabinete empleados por Tomás López.

Además, muchos de los mapas, a pesar de ser elaborados por el Depósito Hidrográfico, van a ser presentados al rey por personajes ilustres de la burocracia española, como el caso de Manuel Godoy (recogido como príncipe de la Paz); Juan de Lángara; Antonio Valdés; Luis María de Salazar, conde de Salazar, etc.

El siglo XviII español supuso para el conjunto de la náutica una época de avance y progreso. Puso coto a un período de decadencia de la marina y la náutica española que había durado hasta el fin de la Guerra de Sucesión (1701-1713). Así, la consolidación de una disciplina náutica institucionalizada, la creación de la Academia de Guardias Marinas, el renovado interés por la ciencia y el apoyo gubernamental a las exploraciones científicas en sucesivas campañas cartográficas van a fomentar la creación de cartas náuticas de enorme calidad y precisión, que se multiplicaron gracias a la Dirección de Trabajos Hidrográficos de la Marina. Es por ello por lo que la mayoría de los historiadores coinciden en denominar al siglo XVIII como «la edad de la cartografía científica» ${ }^{27}$.

De esta forma, la llegada de la Ilustración y la prosperidad económica a España van a suponer un impulso para la renovación cartográfica. Serán personajes como José Patiño y Rosales (secretario de Estado y de Despacho de Felipe V),

27 Buisseret, David: La Revolución Cartográfica en Europa, 1400-1800. La representación de los nuevos mundos en la Europa del Renacimiento, Barcelona, Editorial Paidós, 2004, p. 205. 
el marqués de la Ensenada (secretario de Guerra, Marina, Indias y Hacienda de Fernando VI) o Antonio Valdés (secretario de Estado del Despacho Universal de Marina e Indias) los que iniciarán el período de renovación cartográfica y científica mediante el establecimiento de «... una administración de base territorial que permitiera conocer, ordenar e inventariar sus posesiones para facilitar su control político y su administración ${ }^{28}$. Reordenación que dio lugar a la creación del Tribunal de Contratación de Indias -que sustituyó a la Casa de Contratación-, al establecimiento del primer cuerpo de políticos de la Armada, la Escuela de Navegantes, la Compañía de Guardia Marinas, el Real Instituto y Observatorio de la Armada en 1753 , entre otros ${ }^{29}$.

Con la desaparición oficial de la Casa de Contratación en 1790, el envío de ingenieros, grabadores y militares españoles a estudiar en las academias inglesas, francesas y alemanas y el inicio de las expediciones de exploración y estudio del litoral peninsular y de los territorios de Ultramar, se hizo patente la necesidad de crear una entidad que coordinara la náutica de forma oficial y organizada.

Aunque desde el año 1770 había existido un Depósito Hidrográfico, con la publicación del «Atlas Marítimo de España» de Vicente Tofiño de San Miguel - obra cumbre de la cartografía espańola- urge crear un organismo que coordinara y sistematizara los trabajos hidrográficos y la producción cartográfica. Así, antes de terminar el Setecientos, con el apoyo de los ministros de Marina Valdés y Lángara, nacerá por Real Orden de 17 de diciembre de 1797 la Dirección de Trabajos Hidrográficos, Dirección Hidrográfica o Depósito Hidrográfico, bajo la dirección de José Espinosa y Tello, hasta el año 1815. La función de este centro científico de la Armada era

... la formación o construcción, rectificación, grabado y publicación de las cartas y planos de navegación, así como la redacción de los derroteros, cuadernos de faro, avisos a los navegantes, memorias y resto de las noticias que podían interesar a la navegación de todos los mares, y más especialmente de las posesiones españolas ${ }^{30}$.

Los últimos cuarenta años del Setecientos van a estar marcados por un continuado y sistemático esfuerzo por cartografiar los territorios peninsulares y de Ultramar como una labor de complementación de los descubrimientos. El siglo XVIII culmina con una de las empresas cartográficas y científicas más importantes de la corona: la expedición marítimo-científica de Malaspina y Bustamante (1789-1794), una expedición que remarcó cuál era el valor de la ciencia dentro del esquema ilustrado de la corona. La "ciencia "ilustrada" fue utilizada por el Estado para lograr un

${ }^{28}$ Ródenas Valero, Almudena de la Caridad: «Arte y Ciencia: El Atlas Marítimo de España de Vicente Tofiño de San Miguel», Imafronte, n. ${ }^{\circ}$ 24, 73-102, 2015, p. 76.

${ }^{29}$ Idem.

30 Chain Navarro, Celia y Sánchez Baena, Juan José: «La configuración del primer sistema de información cartográfico naval en España», Tiempos Modernos, Revista electrónica de Historia Moderna, vol. 7 , n. ${ }^{\circ}$ 22, 2011, pp. 1-22. 
mejor conocimiento y mayor control de la administración ultramarina» $»^{31}$. En definitiva, a finales del s. XVIII, la geografía y la astronomía pasaron a ser «instrumentos imprescindibles en las políticas estatales de control del espacio» ${ }^{32}$.

Todo ello supuso, a partir de entonces, editar en España planos y mapas de calidad, actualizados y nuevos, de las costas españolas y de Ultramar, lo cual ponía fin a la dependencia cartográfica extranjera ${ }^{33}$.

Con el inicio del siglo xix culminaría el período de crecimiento científico y cartográfico debido a reveses como la derrota de Trafalgar, la pérdida de las colonias de Ultramar y la invasión francesa. No será hasta el reinado de Isabel II cuando se fomenta el resurgimiento de la ciencia ${ }^{34}$.

\subsubsection{Selección de mapas físico-politicos y militares o teatros de la guerra}

Siguiendo un criterio organizativo, se ha conformado en este fondo cartográfico lo que hemos denominado selección de mapas físico-políticos -coexisten fenómenos naturales y componentes políticos- y militares o teatros de la guerra.

En lo referido a los mapas físico-políticos se han hallado en este fondo cuatro hojas pertenecientes a la Carta general de obras públicas de España, formada por el cuerpo de ingenieros de caminos y canales de 1882 (fig. 6).

La obra, en su totalidad, estaría compuesta por un mapa en dieciséis hojas, a cuatro colores y montado sobre tela, con unas dimensiones de $457 \times 55 \mathrm{~cm}$ en hoja de $63,5 \times 73 \mathrm{~cm}$, y publicado por Real Orden de 9 se septiembre de $1880^{35}$. El meridiano de origen es el de Madrid, con relieve por sombreado y la red hidrográfica principal ${ }^{36}$.

Este mapa representa las carreteras, ferrocarriles y canales, construidos y en construcción, así como los faros, de distinto tipo, de la península ibérica, las islas Baleares, el norte de Francia y Portugal. Actualmente podemos encontrarlo en diferentes instituciones de España, como la Real Academia de la Historia, el Instituto Geográfico Nacional, la Biblioteca Nacional, el Departamento de Cartografía y Artes Gráficas, el Cuerpo de Ingenieros de Caminos, Canales y Puertos de España, entre otras. Hay que destacar que en este fondo lamentablemente solo se conser-

31 Higueras Rodríguez, María Dolores: Marinos cartógrafos españoles, Madrid, Editorial Prosegur, 2002, p. 46.

32 Cuesta Domingo, María del Pilar: José Espinosa y Tello y su aportación a la historia de la hidrografía, Madrid, Universidad Complutense, 2002, p. 355.

33 Ibidem, 356.

34 Ródenas Valero, Almudena de la Caridad: "Arte y Ciencia: El Atlas Marítimo de Espańa...», p. 78.

${ }_{35}$ Manso Porto, Carmen: Real Academia de la Historia. Sección de Cartografía Histórica (siglos XVI-XX), Madrid, Real Academia de la Historia, 2012, p. 164.

${ }^{36}$ Muro Morales, José Ignacio y Casals Costa, Vicente: «Cartografía e Ingeniería», Técnica e Ingeniería en España: El Ochocientos: de los lenguajes al patrimonio, Real Academia de Ingeniería. Institución «Fernando el Católico», Prensas Universitarias de Zaragoza, 2011, p. 148. 


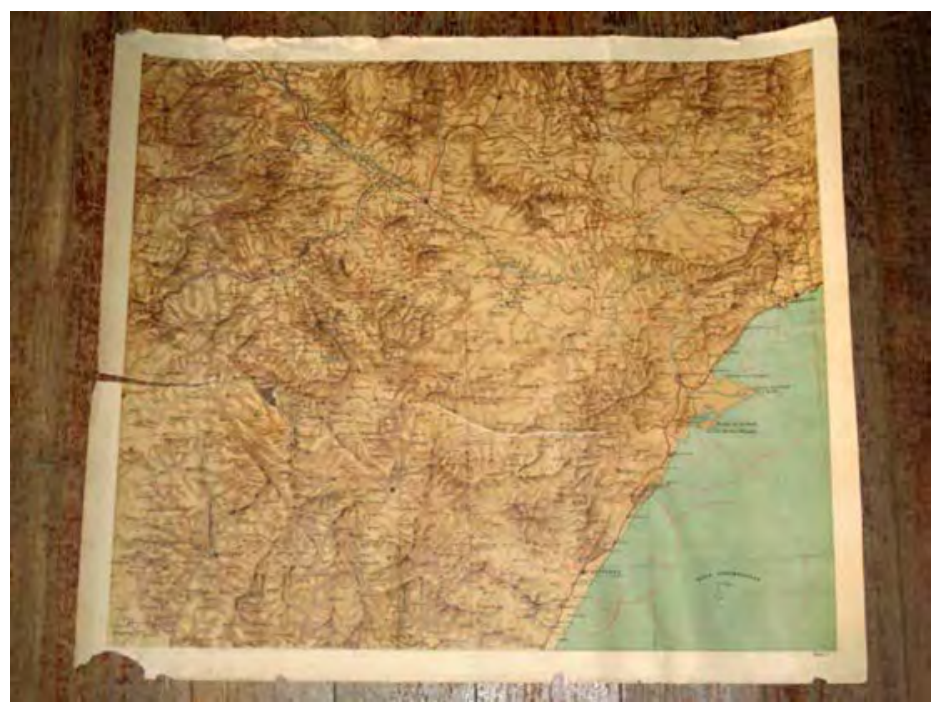

Fig. 6. Mapa perteneciente a la Carta General de Obras Públicas.

van algunas partes del referido mapa, concretamente las hojas 3, 4, 6 y 7, que van a representar a la península ibérica y el norte de Francia.

Dentro de esta selección de mapas físico-políticos hemos ubicado también el hallazgo de cuatro copias del Agricultural Maps of the New South Wales del año 1909, realizado por el Intelligence Departament, Phillip and Bridges Street, Sydney, el cual representa en colores las diferentes zonas de producción de lácteos, zonas de pastoreo y cultivo con regadío, límite de acuíferos artesianos, ferrocarriles, etc., relativos a la geografía de Australia.

En lo que concierne a los mapas de temática militar o teatros de la guerra, hemos identificado cinco mapas militares, atendiendo a su origen o al contexto que representan.

El primero corresponde al territorio de Corea y sur de Manchuria, realizado por los talleres del Depósito de la Guerra. En él aparecen representadas áreas de sondeo, caminos, ferrocarriles, telégrafos, etc.

El segundo es un mapa militar de la isla de La Palma, realizado por los talleres del Servicio Geográfico del Ejército, en el año 1950. Representa territorios, lavas, plataneras, pinares, viñas, etc., de la isla de La Palma.

Los tres mapas restantes van a reflejar distintos momentos de determinadas guerras.

El primero de ellos hace referencia a la guerra Anglo-Boer, constituyendo un croquis del sur de África, publicado por el Depósito de la Guerra el 12 de noviembre de 1899. En este mapa están representados los centros de operaciones, distancias aproximadas de las bases al objetivo, puntos de abastecimiento, obstáculos a encontrar, hospitales, etc. 


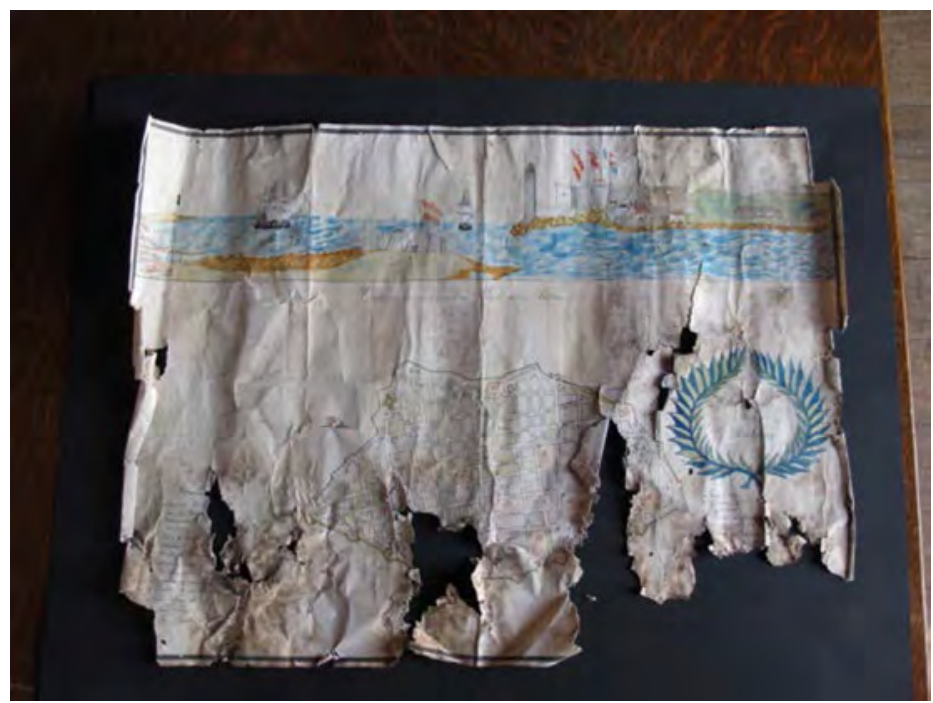

Fig. 7. Mapa manuscrito coloreado del puerto de La Habana.

El segundo, el «Mapa de los diferentes teatros de la Guerra, obsequiado por el Heraldo de Hamburgo a sus lectores», nos ofrece una imagen completa del centro de Europa durante la Primera Guerra Mundial. Se trata de un mapa de considerable importancia ya que va a representar las posiciones de las tropas alemanas el 8 de agosto de 1915, el territorio enemigo ocupado, los territorios de los que el enemigo fue desalojado, una descripción de las pérdidas de la marina de cada uno de los países involucrados, etc.

El tercer mapa, «Mapa del imperio de Marruecos o Moghreb-El-Aksa», realizado por Benito Chías y Carbó, recoge una imagen de la zona del norte de África, en concreto del área marroquí, en la que se representan las residencias del emperador, ciudades importantes, accidentes geográficos, etc.

\subsection{Papeles sueltos de importancia}

Este apartado lo conforma un pequeño grupo de mapas sueltos, que, por sus diversas características, no se ajustan a ninguna de las subdivisiones anteriores, lo que no quiere decir que carezcan de importancia. Ejemplos de algunos de ellos lo constituyen:

- Mapa del puerto de la ciudad de La Habana (fig. 7): se trata de un mapa manuscrito, en malas condiciones de conservación, que impiden conocer su fecha de confección. En él se representa el puerto de la ciudad de La Habana, así como un plano topográfico de la misma. 


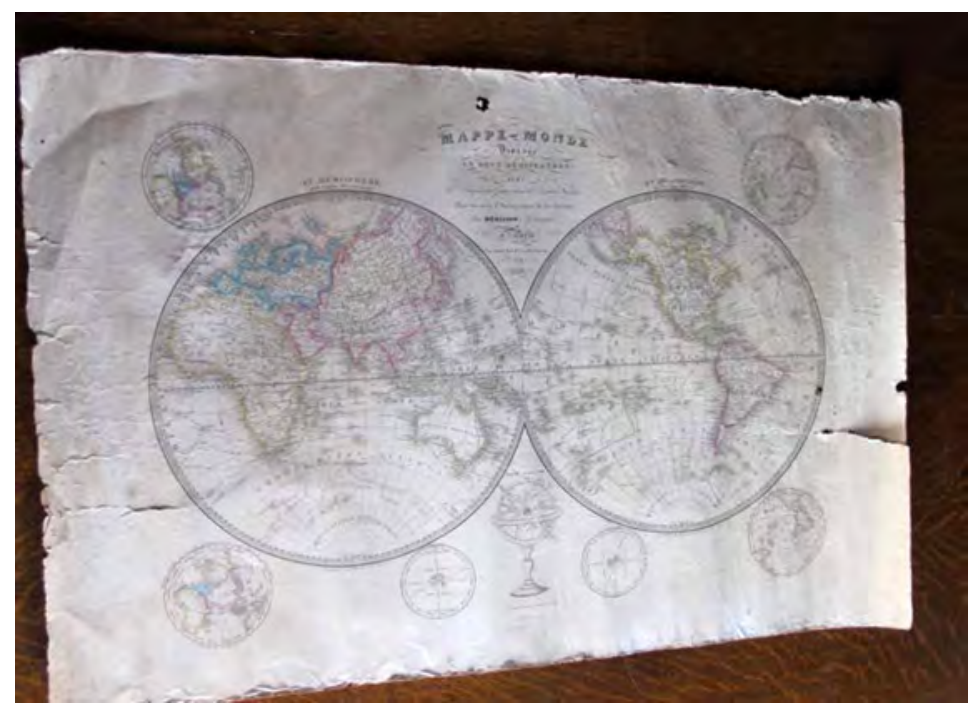

Fig. 8. Mappe-Monde divisée en deux Hemisphères

- Mapa de la epidemia de la peste en Santa Cruz de Tenerife: mapa impreso, en buen estado de conservación, que recoge la geografía de la peste de Santa Cruz de Tenerife. En él se representan numerosos datos sobre la evolución de esta epidemia entre los ańos 1906-1907, entre ellos, antecedentes, relación de infectados, historial de causas, gráfica médica y social, etc.

- Mappe-Monde divisée en deux Hemisphères: mapamundi de origen francés, en buen estado de conservación, realizado por Eustache Hérisson en el año 1838 y en el que se representa la Tierra dividida en dos hemisferios (fig. 8).

- Tableau comparatif de la hauteur des montagnes, de la longueur du cours des fleuves et l'élévation des principales chûtes d'eau dans les cinq parties du monde faisant partie de l'atlas classique: tabla comparativa plegable a gran escala de las montańas, ríos y cascadas del mundo, elaborada en el año 1838 y que se encuentra en buen estado de conservación. En ella, además, aparecen representadas importantes ciudades como París, Roma, Londres o Ginebra. Aunque se basó en la Tableau Comparatif de Bulla de 1826, Monin agregó numerosas anotaciones topográficas y geológicas.

\section{CONCLUSIONES}

En la actualidad existen muchas instituciones regionales -como la que nos ocupa en el presente trabajo, la Real Sociedad Cosmológica de Santa Cruz de La Palma- que son poseedoras de un rico legado bibliográfico, procedente de los diversos avatares por los que ha transcurrido su historia: su evolución lógica, las dona- 
ciones de sus miembros, las desamortizaciones, la inversión de la propia entidad, entre otras, y que por su valor histórico-social van a formar parte de su patrimonio documental.

Con la elaboración de este trabajo pretendemos dar a conocer la existencia de un fondo documental de cartografía, de carácter inédito, perteneciente a la RSC; y, al mismo tiempo, poner en valor la importancia que reviste la conservación de los fondos -como la mayor agrupación documental existente en un archivo o biblioteca- ya que constituyen el patrimonio, la memoria, la identidad y, por supuesto, una fuente de conocimientos.

Hay que decir que los procesos y actuaciones que se han de realizar con este tipo de documentación deben estar encaminados, fundamentalmente, a cumplir tres objetivos: identificar, conservar y difundir. En el caso de la Cosmológica, son diversos los esfuerzos que se han hecho y se hacen para la preservación de los valiosos fondos que atesora, compuestos muchas veces por ejemplares que son escasos y, en ocasiones, únicos; a pesar de la siempre constante escasez de recursos materiales y humanos, para poder hacer frente a la tarea de rescate y conservación de los fondos.

Debemos señalar que la importancia de la limpieza, análisis, ordenación y posterior catalogación de este fondo radica:

En primer lugar, en facilitar a los usuarios el trabajo con los documentos. En ocasiones, los archivos son desconocidos para el público en general e, incluso, para los propios profesionales de las ciencias de la información, ya que la idea que se tiene de los mismos está asociada con el amontonamiento de papeles, cuando en realidad constituyen el lugar donde con esmero se deben tratar, cuidar y custodiar los documentos públicos y privados y, sobre todo, por un personal especializado y conocedor de las técnicas archivísticas. Desafortunadamente, por la falta de espacio y de recursos, muchos fondos documentales -como el que nos ocupa- han tenido que quedar relegados a la espera de poder ser tratados.

En segundo lugar, en proporcionar que la información se comparta y se aproveche como un recurso colectivo. Por sus dimensiones y contenido, sería de gran importancia que este fondo pudiese integrarse a otros sistemas documentales, es decir, a otras instituciones como bibliotecas, archivos, ya sean regionales o centrales, etc., puesto que serviría para completar y complementar la información de los catálogos colectivos.

Y, en tercer lugar, en aprovechar al máximo el valor de los documentos. De ahí la necesidad de que los fondos existentes en las distintas instituciones estén catalogados correctamente, para así facilitar las aproximaciones científicas y de todos los usuarios en general.

Otro aspecto a tener en cuenta es que, en la actualidad, existe una clara necesidad de que los archivos y las bibliotecas se abran al uso de las tecnologías y a la sociedad de la información. Es muy importante proyectar los archivos a la sociedad, como una forma de acercarlos a los ciudadanos y hacer evidente la utilidad de su contenido para la investigación y la cultura. En el caso de este fondo cartográfico, la inclusión de nuevas tecnologías de catalogación, como pueden ser las copias digitales, permitiría compartir la información con otras instituciones, favoreciendo la integración y la divulgación de la documentación. 
Las transformaciones de la nueva sociedad obligan a un desarrollo integral y armónico de los archivos, las bibliotecas, etc., para poder poner a disposición de los usuarios su valioso acervo documental. Lo que no será del todo posible si no se conciencia a las distintas instituciones gubernamentales en la importancia de apoyar la correcta conservación, tratamiento, exposición y divulgación de los fondos que albergan las olvidadas bibliotecas y archivos a nivel regional. Tal es el caso de la Real Sociedad Cosmológica, una institución que carece de los medios más elementales de conservación y manipulación de documentos, como en este caso, los mapas; un tipo de formato en el que se debe tener muy en cuenta que las dimensiones de los contenedores se ajusten a la de los documentos, que deben ser instalados y conservados en lugares aparte y en espacios muy organizados y preparados especialmente para albergar esta clase de documentación.

Por lo tanto, las fuentes documentales -su valoración, conservación y su posterior procesamiento- deben constituir el eje fundamental de la institución que lo custodia. Es vital que los archivos estén ordenados y cuenten con los elementos descriptivos pertinentes que permitan poner al acceso de sus usuarios e investigadores estas importantes fuentes de consulta. Pero también es un imperativo que se dote a estas instituciones de los medios necesarios, como formación, espacios y presupuestos suficientes, para hacer frente a esta documentación. 